\title{
Intestinal Fibrosis in Inflammatory Bowel Disease: The Role of MicroRNAs
}

\author{
Chao Li* \\ Department of Internal Medicine, Medical College of Virginia Campus, Virginia Commonwealth University, Richmond, VA, USA
}

\begin{abstract}
Background \& Aims: Intestinal fibrosis in inflammatory bowel disease (IBD) is due to dysregulation of the wound healing process. MicroRNAs (miRNAs) are essential for the control of many physiological and pathological processes, and they act as critical regulators of gene expression at the post-transcriptional level. However, the role of miRNAs in epigenetic regulation of canonical pathways in intestinal fibrosis remains poorly understood. Here, I review the crosstalk between fibrotic signaling, particularly the transforming growth factor (TGF)- $\beta$ pathway, and miRNAs, highlight potential novel therapeutic targets, and address the challenges of miRNA research. Methods: A combination of different keywords, including "colitis", "microRNA", "IBD", and "fibrosis", was used to search PubMed to obtain highly relevant references for this review. In addition, some critical references cited in highly relevant articles were reviewed as well as abstracts from presentations at recent international conferences. Results: I described the major mechanisms in mesenchymal cells that contribute to fibrotic diseases. I also analyzed the most recent experimental findings from several different in vitro and in vivo models and identify the TGF- $\beta$ pathway as a target at different levels by two kinds of miR-
\end{abstract}

Keywords: MicroRNA; Intestinal fibrosis; TGF- $\beta 1$; Endoplasmic reticulum stress; Epigenetic regulation; Crohn's disease.

Abbreviations: CCL4, carbon tetrachloride; CD, Crohn's disease; CXCL3, chemokine (C-X-C motif) ligand 3; DGCR8, Di-George syndrome critical region gene 8; DNMT1, DNA methyltransferase-1; DSS, dextran sulfate sodium; EMT, epithelial-to-mesenchymal transition; EndoMT, endothelial-mesenchymal transition; ERK, extracellular signal regulated kinase; FBN1, Fibrillin1; FOXO3a, forkhead box O3; HDACi, Histone deacetylase inhibitors; HRE, hypoxia responsive element; IBD, inflammatory bowel disease; IF, immunofluorescence; IGF-1R, insulin-like growth factor 1 receptor; IGFBP5, insulin-like growth factor binding protein 5; ITK, inducible T-cell kinase; KO, knockout; LPT, lamina propria T cells; MIP-2 $\alpha$, macrophage inflammatory peptide- $2 \alpha$; MMPs, matrix metalloproteinases; NF- $\kappa b$, nuclear factor kappa B; NOD2, nucleotide-binding oligomerization domain-containing protein 2; PCR, polymerase chain reaction; PDCD4, the programmed cell death 4; $\mathrm{PH}$, pleckstrin homology domain; PHLPP1, pleckstrin homology domain and leucine-rich repeat protein phosphatase 1; PI3K, phosphatidylinositol 3 kinase; Pre-miRNA, precursor miRNA; PTEN, phosphatase and tensin homology; RISC, RNA-induced silencing complex; RLC, RNA-induced silencing complex-loading complex; SBE, smad binding element; SIP1, smad-interacting protein1; SNP, single nucleotide polymorphism; SOCS1, suppressor of cytokine signaling-1; Spry, signaling by degradation of sprouty; STAT3, signal transducer and activator of transcription 3; TG2, Transglutaminase-2; TGF- $\beta 1$, transforming growth factor- $\beta 1$; TIMPs, tissue inhibitor of MMPs; TNBS, 2,4,6-trinitrobenzene sulfonic acid; UC, ulcerative colitis; UTR, untranslated region; WT, wild type; ZEB1, zinc finger E-box-binding homeobox 1; ZEB2, zinc finger E-box-binding homeobox 2.

Received: 17 August 2015; Revised: 2 October 2015; Accepted: 16 October 2015 ॠDOI: 10.14218/ERHM.2015.00003

*Correspondence to: Chao Li, Division of Gastroenterology, Hepatology and Nutrition Medical College of Virginia Campus, Virginia Commonwealth University, Molecular Medicine Research Building 5-003, PO Box 980341, Richmond, VA 232980341, USA. Tel: +1-804-828-8504, Fax:+1-804-827-0947,E-mail: lic3@vcu.edu
NAs, pro-fibrotic miRNAs: miRNA-21, miR-192, miR-199, miR19 and anti-fibrotic miRNAs: miR-29b, miR-200 family. Finally, I discussed some of the major challenges associated with miRNA research and provide some suggestions. Conclusions: miRNAs may play a critical role in multiple levels of the TGF- $\beta$ pathway in IBD-associated intestinal fibrosis.

\section{Introduction}

Inflammatory bowel disease (IBD), including Crohn's disease (CD) and ulcerative colitis (UC), affects about 2.5 to 3.0 million Europeans and 1.6 million Americans.[1-2] Recent epidemiological studies reported that the incidence and prevalence of IBD are increasing worldwide, making IBD a global disease.[3] The overall health care cost for IBD and necrotizing enterocolitis is estimated to be about $\$ 23$ billion dollars per year, which includes the combined price of medicine and surgery, hospitalization, and loss of productivity.[1-5] CD is an immunologically mediated, chronic remittent, and relapsing inflammatory disease that affects the entire gastrointestinal tract. It is characterized by transmural inflammation with resultant formation of fibrotic stricture and final intestinal fibrosis, which is due to overgrowth of the muscularis layers. This overgrowth is characterized by smooth muscle cell hyperplasia and hypertrophy and excessive deposition of extracellular matrix.[6-10] Chronic inflammation (lifelong)induced muscularis thickening and fibrosis in $\mathrm{CD}$ occurs in the muscularis mucosa and muscularis propria. In this case, a distinctive inflammatory pattern emerges in the intestine, which is subjected to a variety of stimuli, including gut microbiota, genetic mutation, environmental exposure, and chemical contact, and it is mediated by a series of complicated immunological responses and a collaboration of different immune cells.[6-10] Although the mechanism of fibrosis and related issues in $\mathrm{CD}$ have been investigated for several decades, a comprehensive understanding of the pathophysiological mechanisms of intestinal fibrosis remains to be identified and, hence, the exploration of novel therapeutic approaches.[6-10] Here, I summarize the current knowledge on the primary mechanisms of intestinal fibrosis, with a specific emphasis on the role of microRNAs, propose new research pathways and questions, and suggest the potential needs for the study of fibrosis in IBD.

\section{Intestinal fibrosis}

Wound healing is the body's normal response to tissue injury, whereby damaged cells are replaced by cells of similar type and 
Table 1. Protein markers used for identification of Intestine mesenchymal cells

\begin{tabular}{|c|c|c|c|}
\hline Name & Tissues & Significance & Reference \\
\hline$\alpha$-smooth muscle actin ( $\alpha$-SMA) & $\begin{array}{l}\text { 1. Detected in murine small intestine \& colon } \\
\text { 2. Increased expression in radiation induced } \\
\text { enteritis, TNBS, DSS-induced colitis } \\
\text { 3. Can be detected in human normal intestine, UC, CD }\end{array}$ & +++ & $\begin{array}{l}21,22,23 \\
\text { (IHC), } 18\end{array}$ \\
\hline Vimentin & $\begin{array}{l}\text { 1. Can be detected in normal intestine, } \mathrm{UC}, \mathrm{CD} \\
\text { 2. Positive for intestinal myofibroblasts } \\
\text { 3. Positive for fibroblasts }\end{array}$ & + & 22,23 (IHC), 18 \\
\hline Tropomyosin & Can be detected in normal, radiation-induced enteritis. & + & 22 \\
\hline Desmin & $\begin{array}{l}\text { 1. Weaker or negative staining for SEMFs } \\
\text { 2. Positive for SMC. }\end{array}$ & $?$ & 23,18 \\
\hline Smoothelin & $\begin{array}{l}\text { Smooth muscle-specific cytoskeletal protein exclusively } \\
\text { found in differentiated SMC. }\end{array}$ & + & 24,25 \\
\hline S-100 & $\begin{array}{l}\text { Rare expression among intestinal SMC culture; Markers } \\
\text { for inflammatory disease }\end{array}$ & + & 24 \\
\hline
\end{tabular}

CD, Crohn's disease; UC, ulcerative colitis; KO, knockout; DSS, dextran sulfate sodium; TNBS, 2,4,6-trinitrobenzene sulfonic acid; PDCD4, the programmed cell death 4 (PDCD4); MIP-2 $\alpha$, macrophage inflammatory peptide-2 $\alpha$; SIP1, Smad-interacting protein1; ZEB1, zinc finger E-box-binding homeobox 1; IF, immunofluorescence; WT, wild type; NOD2, nucleotide-binding oligomerization domain-containing protein 2; SOCS-1, suppressor of cytokine signaling-1; FOXO3a, forkhead box O3.

by the deposition of ECM.[11-12] Once the fibrotic process is terminated, tissue remodeling occurs through maintenance of a balance between ECM production and its degradation.[11-15] During chronic inflammation, the epithelial and endothelial barriers are disrupted, resulting in activation of intestinal mesenchymal cells, such as smooth muscle cells, fibroblasts, and subepithelial myofibroblasts (SEMFs), by a variety of cytokines, mediators, bacterial products, and growth factors.[16-19] Potential crosstalk between intestinal epithelial cells and SEMFs occurs, as stimulation of epithelial cells inhibits mobility/migration of SEMFs, which potentially contributes to the retention of SEMFs at inflammatory foci in vivo and increased collagen production in SEMFs.[20] Moreover, loss of the negative feedback regulation leads to fibrosis with sustained activation of SEMFs and excess transforming growth factor (TGF)- $\beta 1$ and collagen production and cellular proliferation.[20] Once SEMFs are activated in patients susceptible to fibrostenosis, autocrine mechanisms lead to fibrosis, production of TGF- $\beta 1$ and collagen I, and cellular proliferation, which continues even in the absence of sustained inflammation.[10,16-20] Intestinal fibrosis that is associated with CD is a dynamic tissue remodeling process that is characterized by pathological tissue repair or wound healing process, which depend on the balance between production of ECM components and activity of proteolytic enzymes, such as matrix metalloproteinases (MMPs) and tissue inhibitor of MMPs (TIMPs).[11-15] More specifically, reduced MMP activity and/or upregulated TIMP protein levels appear to contribute to dense collagen deposition during stricture formation. Intestinal fibrosis in CD-associated strictures requires activated ECM-secreting myofibroblasts to perpetuate the fibrotic response and to sustain tissue remodeling and stricture formation.[16-19] Crosstalk between colonic epithelial cells and subepithelial myofibroblasts may recruit other cell types to differentiate into active myofibroblasts through several molecular mechanisms, including epithelial-to-mesenchymal transition (EMT) and endothelial-mesenchymal transition (EndoMT), defective apoptosis, enhanced proliferation of myofibroblasts, mesenchymal cells migration into inflamed region, and intestinal stem cells differentiation.[16-19] In Table 1, I summarize protein markers used to identify major components of mesenchymal cells that contribute to intestinal fibrosis.[21-25]

\section{TGF- $\beta$ signaling}

TGF- $\beta$ and its downstream signals play a key role in wound healing and tissue repair.[26-35] In addition to its plethora of effects on the dynamic interaction among immune and nonimmune cells, it has been found in all cell types involved in fibrotic lesion.[32-35] We and others have reported multiple mechanisms regarding the activation of TGF- $\beta$ in IBD.[31-33] Integrin induces fibrogenesis through integrin binding to the arginine-glycine-aspartate (RGD)binding domain of N-terminal latency associated peptide (LAP)TGF- $\beta$, resulting in release of active TGF- $\beta$ from its complex, binding of active TGF- $\beta$ to its cognate receptors on the cell membrane, and subsequent signal transduction signals.[32-33] Even though all the isoforms of TGF- $\beta$ are detectable in fibrotic tissues, including $\mathrm{CD}$, the major factor involved in fibrogenesis is TGF- $\beta 1 .[23]$ Moreover, mRNA expression and protein levels of TGF- $\beta 1$ in strictured colon are significantly upregulated relative to normal colon and normal resection margin from the same patient with $\mathrm{CD}$. Gene transfer of TGF- $\beta 1$ has also been shown to reproduce experimental colitis in mice.[34] Bidirectional functional crosstalk between TGF- $\beta$ signals and aberrant expression of microRNAs (miRNAs or miRs) has been reported in a variety of human diseases and animal models, including multiple organ fibrosis.[36-37] The TGF- $\beta$ pathway has been documented to regulate many miRNAs, including miR15/16, miR-21, miR-29b, miR-17 92, miR-106-25, miR-155, miR-181b/d, miR-199a, miR-224, and the miR-200 family.[36]

\section{MicroRNA biogenesis and function in physiologcial and pathological conditions}

miRNAs are small non-coding (18-25 oligonucleotides) RNAs found in metazoans and represent a family of distinctive non-coding RNAs. A number of well-written reviews have presented the general biogenesis of miRNA.[38-44] Therefore, I will provide only a brief introduction here. In general, miRNAs are transcribed into primary miRNA (pri-mRNA) about 100 nucleotides in length in the nucleus by RNA polymerase II. Pri-miRNAs contain characteristic stem-loop or hairpin structures that are cleaved in the 
nucleus by the RNAse type III enzyme Drosha and the RNA binding protein Di-George syndrome critical region gene 8 (DGCR8) to generate a 60-70 nucleotide hairpin loop sequence called precursor miRNA (pre-miRNA). Then, exportin-5, a RanGTP complex, transports pre-miRNAs from the nucleus to the cytoplasm, where the hairpin loop is further cleaved into 19-25 nucleotide miRNA-miRNA* duplexes by RNA-induced silencing complex (RISC)-loading complex (RLC) and other factors containing Drosha. While the miRNA* strand is degraded in the cytoplasm, the mature miRNA strand guides the RNA-induced transcriptional silencing complex to bind to promoter-associated mRNA transcripts at the $3^{\prime}$-untranslated region (UTR) or 5'-UTR elements, or both, via complementary 6-8 nucleotide sequence.[38,39] These short RNAs play a diverse role in the development of physiological and pathological conditions and exert epigenetic post-transcriptional regulation of gene expression.[40-41] The "seed sequence", typically $6-8$ nucleotides, binds to complementary partial sequences in the 3'-UTRs of targeted mRNAs, resulting in translational repression or mRNA degradation. It is in this way that miRNAs control protein production. Up to $60 \%$ of human protein coding genes are regulated by over 2,500 known mature human miRNA transcripts (miRbase release 20). Aberrant miRNA expression plays an important role in the progression and phenotype distribution of many diseases, including several autoimmune diseases, cancer, multiple organs fibrosis, and IBD. To date, studies have identified distinct tissue and plasma miRNA expression patterns in patients with IBD. A number of miRNAs including, miR-21 and miR-29 family members, have been reported as common modulators of organ fibrosis in different diseases and animal models.[42-44] Epigenetic regulation of miRNA expression through chromosomal aberration, DNA methylation, transcription factor binding, and histone modification are associated with dysregulation of targeted gene expression.[45-47] For example, hypermethylation of miR-199a-5p by DNA methyltransferase-1 (DNMT1) in testicular cancer cells (NT2) led to suppression of cancer cell growth, cancer migration, invasion, and metastasis.[48]

Given the critical role of miRNAs in normal and diseased conditions, it is not surprising that miRNAs have multifaceted functions in the pathogenesis of IBD. Unique miRNA expression profiles in tissue samples and peripheral blood have been reported for patients with $\mathrm{UC}$ and $\mathrm{CD}$, allowing for the differentiation of IBD diagnosis.[49] Epigenetic regulation of miRNA expression and a critical role of miRNAs in the development and differentiation of immune responses have been uncovered by studies on Th17 signaling, autophagy, and related transcription factors, such as nuclear factor kappa B (NF-kb) and signal transducer and activator of transcription 3 (STAT3).[40,50] During intestinal barrier dysfunction, the expression of miR-21 is increased, impairing tight junction integrity and increasing barrier permeability through targeting the Rho GTPase RhoB.[51] The study of the role of miRNAs in IBD has received much attention in the field, but the state of research is still in its infancy. Even though there has been much progress in anti-inflammatory treatments of IBD in clinical trials and practice, the frequency of stricture complication postsurgery and after immunotherapy is still high; and no cure that targets fibrosis is currently available.[7-10] One reason for the lack of a curative treatment is because the mechanism of intestinal fibrosis and the role of miRNAs in this process remain poorly understood.

\section{Epigenetic regulation of intestinal fibrosis}

Our understanding of the biological functions of intracellular miR-
NAs has increased considerably in the last two decades. A growing body of evidence indicates that miRNAs contribute to several cellular processes related to apoptosis, cell proliferation, cell cycle regulation, differentiation, autophagy, unfolded protein response, and the innate and adaptive immune systems.[45-47] However, the role of miRNAs in the development of intestinal fibrosis in IBD remains largely unknown. The rapidly developing field of epigenetics has demonstrated the great potential for elucidating pathological mechanisms of abnormal gene expression due to the changes of the structure and function of chromatin caused by environmental factors. Epigenetic mechanisms effect gene expression and cellular function through three distinct and interconnected mechanisms: 1) chromatin structure modulation, 2) DNA methylation, and 3) RNA interference by noncoding RNAs.[45-47] There is growing evidence showing that intestinal fibrosis is modulated by epigenetic mechanisms. Histone deacetylase inhibitors (HDACi) were shown to reduce the mRNA and protein levels of collagen I and the resultant fibrosis in several animal models of fibrosis.[45-47] HDACs are also involved in EMT and fibroblast activation and differentiation, but the underpinning mechanisms remain unknown. Sadler et al. showed that epigenetic/chromatin changes with histone modification and induction of the collagen $1 \mathrm{~A} 2$ gene are required for and are important regulators of intestinal EMT.[52] About 10\% of miRNA expression is intricately controlled by DNA methylation through DNMTs, which are responsible for both $\mathrm{CpG}$ and non-CpG methylation.[40] In an IBD study, Kalla et al. identified among the 65 differentially methylated CpG sites with epigenome-wide significance a correlation between the hypomethylated miR-21 locus and expression of miR-21 expression in leucocytes and affected mucosa.[40] Taken together, these findings suggest that intestinal fibrosis can be modulated at the epigenetic level in IBD.

\section{Functional studies on the role of mirnas in fibrosis of IBD}

Although the link between many miRNAs and multiple organ fibrosis, including lung, kidney, heart, liver, and systemic sclerosis, has been studied, there are few studies available that investigate the association with intestinal fibrosis.[38-41] Here, I summarize the miRNAs associated with intestinal fibrosis (Table 2). These miRNAs can be divided into "profibrotic" and "antifibrotic" categories, based on their role related to intestinal fibrosis. Profibrotic miRNAs are miRNA-21, miR-192, miR-199, and miR-19, and antifibrotic miRNAs are miR-29b and the miR-200 family. Due to shared pathways in organ fibrosis, miRNAs that have a potential role in intestinal fibrosis are worthy of investigation including miR192, miR-143/145, miR-210, miR-155, miR-199a, miR-19.

\section{$\operatorname{miR}-21$}

miR-21 is probably the most widely studied miRNA in IBD, demonstrating consistent and reproducible functional findings in animal models. These data demonstrate that mir- 21 may be a potential therapeutic target for fibrosis in multiple organs and other diseases, such as cancer.[42,44,51,53-56] The role of miR-21 in organ fibrosis is based on accumulating evidence on pulmonary, cardiac, and renal fibrotic disorders.[42,44,51,53-56] Upregulation of miR-21 expression was observed in affected human tissues as well as in mouse models of fibrosis in different organs.[42,44,51,53-56] Inhibition of miR-21, either by a miR-21 antagomir or antisense oligonucleotides, reduced and even prevented the progression of 
Table 2. Selected summary of aberrant miRNAs associated with intestinal fibrosis in IBD

\begin{tabular}{|c|c|c|c|c|c|c|}
\hline microRNA & Human tissue & Expression level & Target & Pathway/function & Methods & Reference \\
\hline miR-21 & $\begin{array}{l}\text { Ileal CD tissue with } \\
\text { different phenotypes }\end{array}$ & Increased & $\begin{array}{l}\text { Smad7, } \\
\text { Smad3, RhoB, } \\
\text { PDCD4 }\end{array}$ & TGF- $\beta$, Th1 & $\begin{array}{l}\text { qRT-PCR, } \\
\text { DNA-ChIP }\end{array}$ & $51,53,56$ \\
\hline $\begin{array}{l}\text { miR-29/ } \\
\text { miR-29b }\end{array}$ & $\begin{array}{l}\text { Mucosa overlying strictures, } \\
\text { mucosal fibroblasts, human } \\
\text { dendritic cells from CD }\end{array}$ & Reduced & $\begin{array}{l}\text { Collagen I and } \\
\text { III, Smad3, IL- } \\
\text { 12p40, IL-23 }\end{array}$ & TGF- $\beta$, EMT & qRT-PCR & $57,60-61$ \\
\hline $\begin{array}{l}\text { miR-200 } \\
\text { family }\end{array}$ & $\begin{array}{l}\text { Intestinal epithelial cells, } \\
\text { intestinal biopsies }\end{array}$ & Decreased & $\begin{array}{l}\text { Smad2, } \\
\text { E-cadherin, } \\
\text { ZEB1 }\end{array}$ & TGF- $\beta$, EMT & qRT-PCR & 65 \\
\hline miR-192 & $\begin{array}{l}\text { Active UC tissue, } \\
\text { colonscopic pinch biopsies } \\
\text { from the } \\
\text { sigmoid colon }\end{array}$ & Downregulated & $\begin{array}{l}\text { MIP-2 } \alpha, \text { SIP1, } \\
\text { NOD2, Smad3 }\end{array}$ & Cytokine production & $\begin{array}{l}\text { qRT-PCR, } \\
\text { in situ } \\
\text { hybridization }\end{array}$ & $49,67-69$ \\
\hline $\begin{array}{l}\text { miR- } \\
143 / 145\end{array}$ & Intestinal mesenchymal cells & Decreased & $\begin{array}{l}\text { IGFBP5, PI3K } \\
\text { /Akt }\end{array}$ & IGF & qRT-PCR & 73 \\
\hline miR-155 & $\begin{array}{l}\text { Intestinal myofibroblasts, } \\
\text { colonic mucosa pinch } \\
\text { biopsy, intestinal } \\
\text { epithelial HT29 cells }\end{array}$ & Increased & $\begin{array}{l}\text { FOXO3a, } \\
\text { IL- } 8 \\
\text { I } \mathrm{B} \alpha\end{array}$ & Th17 & qRT-PCR & $80-81$ \\
\hline miR-19b & $\begin{array}{l}\text { Intestinal pinch biopsy, } \\
\text { intestinal epithelial cells }\end{array}$ & Decreased & SOCS3 & JAK/STAT & qRT-PCR & 92 \\
\hline microRNA & Animal model & Expression level & Target & Pathway/function & Methods & Reference \\
\hline miR-21 & $\begin{array}{l}\text { miR-21 KO DSS, TNBS, T } \\
\text { cell transfer murine model of } \\
\text { colitis }\end{array}$ & $\begin{array}{l}\text { Increased in } \\
\text { TNBS }\end{array}$ & RhoB, CDC42 & TGF- $\beta$, Th1 & $\begin{array}{l}\text { qRT-PCR, } \\
\text { microRNA } \\
\text { array }\end{array}$ & 44,55 \\
\hline $\begin{array}{l}\operatorname{miR}-29 / \\
\text { miR-29b }\end{array}$ & $\begin{array}{l}\text { Colonic tissue from miR-29 } \\
\text { KO murine models }\end{array}$ & Reduced & $\begin{array}{l}\text { IL-12p40, } \\
\text { IL-23 }\end{array}$ & Th17 & qRT-PCR & 57 \\
\hline $\begin{array}{l}\text { miR- } \\
143 / 145\end{array}$ & Murine DSS colitis & Decreased & PI3K/Akt & IGF & qRT-PCR & 74 \\
\hline $\operatorname{miR}-210$ & $\begin{array}{l}\text { CD4+T cells, T cell transfer } \\
\text { model of colitis }\end{array}$ & Increased in WT & HIF-1 $\alpha$ & Th17 & qRT-PCR & 76 \\
\hline miR-155 & miR-155 KO mice & Increased in WT & IL-23, TGF- $\beta$ & Th1/Th17 & qRT-PCR & 79 \\
\hline
\end{tabular}

experimental organ fibrosis in different mouse models.[44,53,55] The precise mechanisms of how profibrotic miR-21 contributed to multiple organ fibrosis may be related to several putative pathways and targets. Since TGF- $\beta$ has been shown to induce miR-21 expression in cultured cells, including human intestinal myofibroblasts, the TGF- $\beta /$ Smad canonical pathway is one of the most studied mechanisms of miR-21 function in the development of fibrosis.[53] MiR-21 repressed Smad7 expression while increased Smad3 upregulation through binding to the Smad binding element (SBE) located in the promoter region of Smad3.[53] In carcinoma-associated fibroblasts (CAFs), miR-21 bound to the 3'-UTR of Smad7 and inhibited its translation, but it did not cause its degradation.[54] MiR-21 also enhanced fibrosis through other noncanonical pathways, such as activation of extracellular signal regulated kinase (ERK) and phosphatidylinositol 3 kinase (PI3K)/ AKT signaling by degradation of sprouty (Spry) and phosphatase and tensin homology (PTEN), respectively.[42] Regarding IBD, miR-21 has been shown to play a role in inflammation and tissue injury. miR-21 impairs the tight junction integrity and increases barrier permeability through targeting the Rho GTPase RhoB.[51] Global deletion of miR-21 in mice is protected in dextran sodium sulfate (DSS)-induced colitis but exacerbated in intestinal inflammation in both the 2,4,6-trinitrobenzene sulfonic acid (TNBS) and $\mathrm{T}$ cell transfer colitis models.[44] Interestingly, another target of miR-21, proinflammatory programmed cell death 4 (PDCD4), was reported in macrophages, suggesting that there are unexpected anti-inflammatory properties of miR-21 in different cell types.[56] The differential effects of miR-21 in different conditions may reflect diversified pathogenic pathways implicated in each model of colitis, distinctive roles of specific cell types, and preferred targets of miR-21 in specific cell types.[44]

miR-29

miR-29 has three mature members, miR-29a, miR-29b, and miR$29 \mathrm{c}$ that are encoded by two distinct genomic loci.[43] In multiple organs, miR-29 expression was enriched in mesenchyme-derived cells.[43] The promoter regions of miR-29 genes serve as multiple binding sites for several transcription factors, including NF- $\kappa B$ and Smad3.[43] Moreover, growth factors or cytokines, such as TGF- $\beta$, TNF- $\alpha$, and interleukin (IL)-4, suppress miR-29 expres- 
sion.[43] There are 11 ECM-related genes among the list of the top 30 predicted targets of miR-29, including eight collagens, elastin, fibrillin1 (FBN1), and peroxidasin, which are the major components of ECM.[43] These distinctive features make miR-29 a perfect candidate for anti-fibrotic therapy. The role of miR-29 in the prevention of tissue fibrosis was shown in mouse models of renal, cardiac, liver, and pulmonary fibrosis through inhibition of TGF$\beta$-mediated ECM production and deposition.[43,57-60] Within the context of IBD study, studies in the miR-29 knockout mouse helped us to understand further the role of miR-29 in intestinal fibrosis.[57] Using a dendritic cell line, Brain et al. found that nucleotide-binding oligomerization domain (NOD-2) induced miR29 release and limited IL-23 release. More importantly, NOD2 polymorphism decreased the miR-29 expression and increased the risk of stricture formation in patients with CD.[57] NOD2 polymorphisms in $\mathrm{CD}$ are associated with a stricturing phenotype that is characterized by severe intestinal fibrosis.[58] NOD2 also influences the composition of the microbiome.[59] Therefore, this pioneering study indicated a novel role of miR-29 in microbiome function in intestinal fibrosis. Nijhuis et al. reported reduced miR29 family expression in the mucosa overlying strictures compared to adjacent nonstrictured areas. Stimulation with TGF- $\beta$ significantly increased collagen $1 A 2$ and $3 A 1$ gene expression through downregulation of miR-29b in isolated mucosal fibroblasts from patients with stricture.[60] These data are in line with previous findings showing that reduced levels of miR-29 are associated with multiple organs fibrosis.[43,61-62]

Regarding the potential profibrotic role of miR-21 and antifibrotic role of miR-29b in fibrosis, our group studied the function of miR-21 and miR-29b in intestinal fibrosis of CD. Differential expression pattern of miR-21 and miR-29b were identified in subepithelial myofibroblasts from fibrostenotic phenotype of $\mathrm{CD}$ compared to normal resection margin within the same patient as well as other phenotypes. Smad3 gene was identified as the posttranscriptional target for both miRNAs.[61]

\section{miR-200 family}

Members of the miR-200 family (miR-141, miR-200a, miR-200b, miR-200c, and miR-429) are associated with multiple organ fibrosis and EMT, common features shared by fibrosis and tumor metastasis.[63-66] The inhibition of the E-cadherin transcriptional repressors zinc finger E-box binding homeobox (ZEB)1 and ZEB2 is considered a mechanism by which the miR-200 family suppresses fibrosis.[63] Within the context of IBD, miR-200b was shown to promote the growth of intestinal epithelial cells by inhibiting EMT via TGF- $\beta$. Expression of these miRNAs was decreased significantly in cultured cells showing EMT activity in the presence of TGF- $\beta$.[65] Wang et al. used a reporter gene assay to show that the miR-200 family contributes to fibrosis by directly targeting TGF- $\beta 2$.[66] In their study, exogenous overexpression of both miR-141 and miR-200a in rat proximal tubular epithelial cells (NRK52E) reduced TGF- $\beta 2$ and Smad 3 activity and ECM protein levels and prevented EMT. The decreased expression of miR-200 family may be partially related to DNA hypermethylation at the promoter regions of these miRNAs in fibrotic disorders.[66]

\section{$\operatorname{miR}-192$}

Wu et al. found a significant reduction of miR-192 expression in active UC tissues and an inverse correlation between miR-192 expression and macrophage inflammatory peptide-2 $\alpha$ (MIP-2 $\alpha$ ), which is produced by colonic epithelial cells and macrophages and highly expressed in active UC tissues relative to healthy control tissues.[49] However, overexpression of miR-192 in colonic epithelial HCT116 cells suppressed NOD2 expression, muramyl dipeptide-mediated NF- $\mathrm{NB}$ activation, and gene expressions of IL-8 and chemokine (C-X-C motif) ligand 3, CXCL3.[67] A single nucleotide polymorphism (SNP) (rs3135500) located in the NOD2 3'-UTR significantly decreased the effect of miR-192 on NOD2 mRNA level.[67] Interestingly, in glomerular mesangial cells, miR-192 was upregulated by TGF- $\beta$ through induction of ets- 1 expression under diabetic conditions.[68] In the same study, TGF- $\beta$ treatment or transfection with miR-192 decreased expression of Smad-interacting protein 1 (SIP1), a novel target of miR-192 that is structurally similar to another E-box transcriptional repressor, $\delta E F 1$, i.e., the transcription factor ZEB1.[68] Further, Arthur et al. reported in tubular epithelial cells that $\mathrm{Smad} 3$, but not $\mathrm{Smad} 2$, mediated TGF- $\beta 1$-induced miR-192 expression through binding to the Smad-binding sites in the miR-192 promoter.[69] In addition, miR192 was shown to be highly expressed in the kidney and liver.[70] Interestingly, in vitro treatment with anti-miR-29b, miR-21, and miR-192 mimics inhibited the effects of Smad7 overexpression on renal fibrosis in tubular epithelial cells, which suggests that these microRNAs act downstream of Smad7 to override Smad7 function. Restoration of renal miR-29b with suppression of miR-192 and miR-21 may be the mechanism for Smad7 gene therapy inhibition of renal fibrosis.[71] Taken together, these findings suggest that caution should be taken before we consider miR-192 as a potential therapeutic target for anti-inflammation due to its unwanted profibrotic effects and tissue specific expression pattern.

\section{$\operatorname{miR}-143 / 145$}

Previously, Qian et al. showed that insulin-like growth factor 1 receptor (IGF-1R) was the direct target of miR-143 and that its expression was inversely correlated with miR-143 expression in human colorectal tumor tissue.[72] Two recently published articles discussed the role of miR-143/145 in the pathogenesis of colon cancer in vitro and in vivo. In mice with constitutional or tissue-restricted deletion of miR-143/145, Chivukula et al. found that excessive secretion of insulin-like growth factor binding protein 5 (IGFBP5) by mesenchymal cells of the intestine, including myofibroblasts, resulted in decreased phosphorylation of epithelial IGF1R, which may contribute to defects in epithelial regeneration due to impaired IGF signaling after epithelial injury.[73] In the azoxymethane (AOM)/DSS-induced mouse model of colitis-associated cancer, Josse et al. identified PI3K/Akt and IGF1 as major signaling pathways affected by downregulation of miR-143/145 and other miRNAs.[74] Moreover, they also found that miR-143 can affect the PI3K/Akt pathway in an IGF-1R independent manner.

\section{$\operatorname{miR}-210$}

miR-210 is considered a signature of hypoxia and a master "hypoxamiR", which is a subset of miRNAs induced by hypoxia.[75] HIF-1 $\alpha$ was shown to upregulate miR-210 through its binding to the hypoxia responsive element (HRE) located on the proximal promoter of miR-210.[75] Wang et al. identified Hifla as a novel target of miR-210, suggesting that miR-210 can inhibit HIF-1a expression through a negative feedback loop. Deletion of miR-210 promoted Th17 differentiation under hypoxic conditions. In a T cell transfer model of colitis, miR-210 was demonstrated to be an 
important regulator of $\mathrm{T}$ cell differentiation via reducing Hifla mRNA levels and the number of cells that produced inflammatory cytokines, thereby limiting intestinal immunopathology.[76] Study of primary mesenchymal cells isolated from patients with idiopathic pulmonary fibrosis (IPF) showed that increased miR210 expression drove fibroblast proliferation by repressing the c-myc inhibitor (MNT), while knockdown of miR-210 decreased hypoxia-induced IPF fibroblast proliferation and correlated with increased MNT expression.[77]

\section{$\operatorname{miR}-155$}

In an early study, Das et al. showed that TGF- $\beta$ induced miR-155 in lamina propria T cells (LPT) and that T-cell miR-155 overexpression decreased mRNA levels of IL-2 and inducible T-cell kinase (ITK), a functional target of miR-155. Antagonism of miR155 restored the levels of both mRNAs in activated cells. [78] In the DSS colitis model in miR-155 knockout mice, the number of Th1/Th17, CD11 ${ }^{\mathrm{b}+}$, and CD11 ${ }^{\mathrm{c}+}$ cells was decreased, consistent with attenuation of intestinal damage from experimental colitis.[79] In one of two human UC studies, Min et al. found that miR-155 downregulated forkhead box O3a (FOXO3a) and activated the NFKB pathway in active UC tissues.[80] Moreover, the level of miR-155 was increased in intestinal myofibroblasts isolated from patients with active UC relative to those from healthy control and $\mathrm{CD}$ patients, through downregulation of suppressor of cytokine signaling-1 (SOCS1).[81] Paraskevi et al. reported that miR-155 was the most highly expressed of the six UC-associated miRNA in blood samples using real-time polymerase chain reaction (PCR).[82]

\section{miR-199a}

Most studies on the role of miR-199a in fibrosis were performed in pulmonary and liver fibrosis. Zhang et al. identified the AKT/miR$199 \mathrm{a}-5 \mathrm{p} /$ caveolin 1 pathway as a regulator of innate immunity that is dysregulated in cystic fibrosis macrophages, which contributes to the lung hyper-inflammation response.[83] MiR-199a-5p expression was induced with TGF- $\beta$ exposure, and ectopic expression of miR-199a-5p was sufficient to promote the pathogenic activation of pulmonary fibroblasts, including proliferation, migration, invasion, and differentiation into myofibroblasts. In addition, miR-199a-5p is also a key effector of TGF $\beta$ signaling in lung fibroblasts by regulating caveolin 1 , a critical mediator of pulmonary fibrosis.[84] In both studies of carbon tetrachloride $\left(\mathrm{CCL}_{4}\right)$-induced mouse model of liver fibrosis and human liver tissue biopsies from patients with $\mathrm{HCV}$ infection, the expression levels of miR-199a, 199a*, 200a, and 200b were increased.[85] A recent study showed that miR-199a-5p targeted the pleckstrin homology (PH) domain and leucine-rich repeat protein phosphatase 1 (PHLPP1). PHLPP1 is a tumor suppressor that negatively regulates the AKT pathway and may render colon cancer cells insensitive to treatment with the epidermal growth factor receptor inhibitor cetuximab (CTX).[86]

\section{miR-19}

The miR-19 family (miR-19a and miR-19b-1) was identified as the key oncogenic component of the polycistronic miR-17 92 cluster.[87] Exogenous expression of miR-19, including miR-19a and miR-19b-1, in lung cancer cells triggered EMT, as shown by mes- enchymal-like morphological conversion, downregulation of epithelial proteins, upregulation of mesenchymal proteins, formation of stress fibers, and reduction of cell adhesion.[88] Transglutaminase-2 (TG2), a critical cross-linking enzyme in ECM and tumor microenvironment was identified as a target for miR-19 by in silico analysis and was confirmed by a functional study.[89] Overexpression of pre-miR-19a in a cell model of metastatic colon cancer and decreased TG2 expression were linked to chromosome-13 amplification events, leading to enhanced invasion.[89] A recent study in CD showed low serum levels of miR-19a-3p and that miR-19b$3 p$ was associated with a stricturing phenotype of $\mathrm{CD}$ and could be used as a potential circulating marker for stricturing CD.[90] This low level of miR-19 in serum may be associated with active DNMT-1 expression and methylation of the miR-17 92 promoter, which was identified in human IPF tissue and fibroblasts and mouse fibrotic lung tissue.[91] Cheng et al. found that miR-19b directly recognized the 3 '-UTR of SOCS3 and inhibited its expression, leading to increased macrophage-inflammatory protein-3 $\alpha$ (MIP-3 $\alpha$ ) and suppression of inflammatory response in intestinal epithelial cells.[92]

These aforementioned studies shed light on developing therapeutic methods in fibrotic diseases. Spatial and temporal expression of specific miRNAs in the gut play a critical role in orchestrating fundamental cellular processes and maintaining intracellular homeostasis before they are dysregulated in the pathological conditions of fibrosis.

Based on previous findings of different miRNAs in epigenetic regulation of TGF- $\beta$ and EMT, I hypothesized potential mechanisms of profibrotic and antifibrotic miRNAs in the regulation of TGF- $\beta$ signals at multiple levels in the development of intestinal fibrosis in IBD. In Fig. 1, profibrotic miRNAs, such as miR-21, miR-199a, and miR-192, enhance TGF- $\beta$ signals at different levels by targeting not only the upstream TGF- $\beta$ receptor, Smad3, or the integral membrane protein, caveolin 1, but also downstream fibrotic gene products and collagens. The fibrotics miR-19 and miR-192 may target EMT/ZEB family members. In contrast, antifibrotic miRNAs may inhibit the same molecules in TGF- $\beta$ signaling. For example, miR-29b may inhibit multiple targets (mainly ECM-related genes) during TGF- $\beta$ signaling activation. In summary, the epigenetic dysregulation of profibrotic and antifibrotic miRNAs regulates TGF- $\beta$ signaling during the development of intestinal fibrosis. Better understanding of the role of different miRNAs and the regulation of aberrant expression of miRNAs may provide us novel insights into the mechanism(s) underlying intestinal fibrosis, potential therapeutic target(s), and a promising diagnostic or evaluation tool before and after treatment for IBD patients, specifically with fibrostenotic CD.

\section{Challenges in microRNA research}

Currently, the field of miRNA research is growing dramatically, as shown by the stunning number of miRNA-related publications covering almost all biomedical research topics found in PubMed. The importance of miRNAs in normal physiology and disease is already known.[38-41] However, in order to understand the role of individual miRNAs in intestinal fibrosis of IBD, we have to consider real challenges that need to be overcome in miRNA research. First, it is difficult to interpret and compare the profile of miRNAs among different groups because there is a lack of standardization of experimental design and data analysis, such as different concepts of control groups and different approaches to normalize miRNA data. Second, it is difficult to evaluate contradictory data 


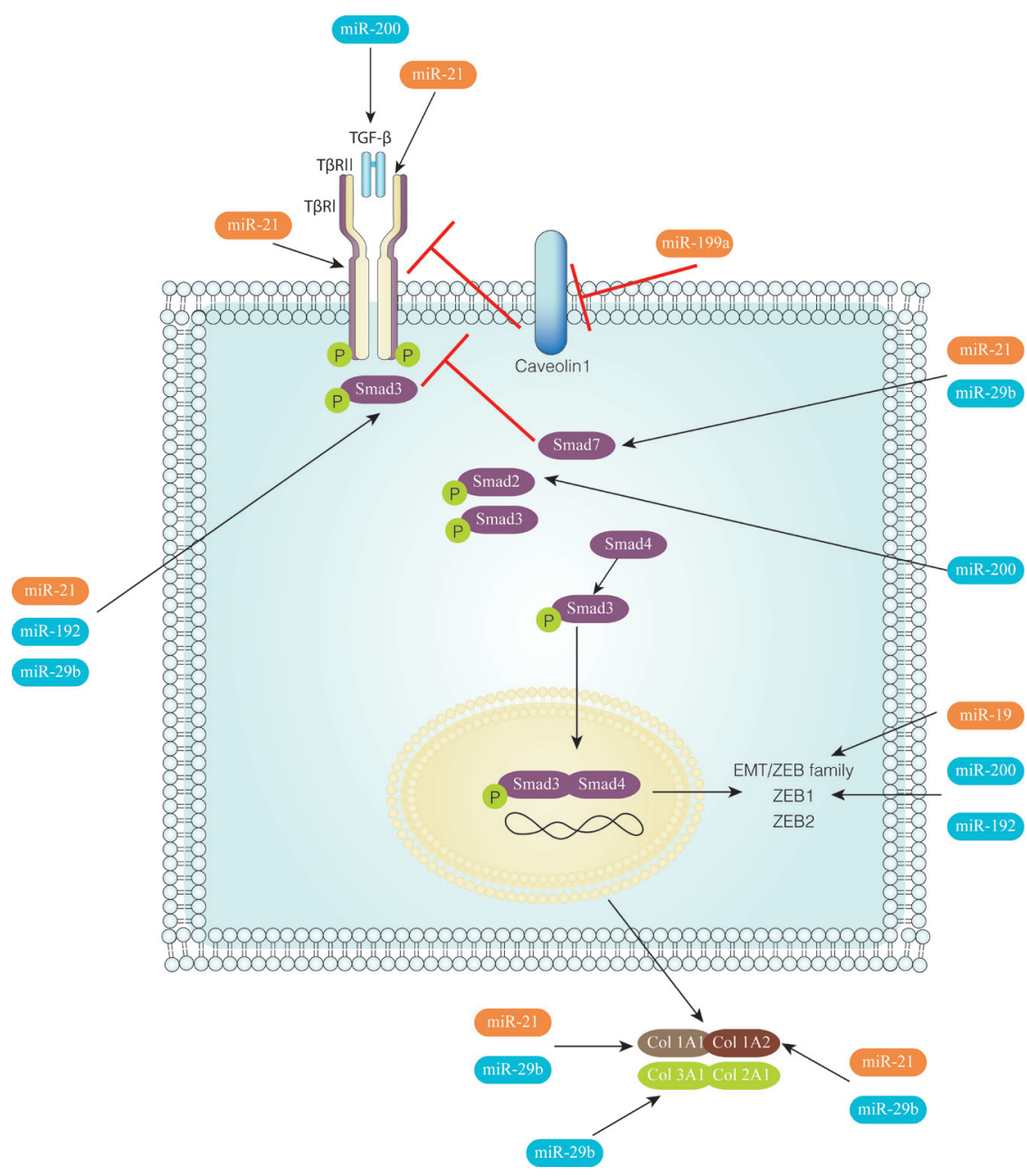

Fig. 1. Aberrant microRNA expression may positively or negatively regulate gene expression in the transforming growth factor beta (TGF- $\beta$ ) signaling pathway at multiple levels in inflammatory bowel disease (IBD) patients (refer to the main text for further details of our hypotheses).

related to individual miRNA expression patterns in different organ systems or in samples of different origins (serum vs. tissue biopsies and immune cells vs. mesenchymal cells) due to cell-typespecific and tissue-type-specific expression of miRNA.[40] Third, targeted delivery of miRNAs of interest in vivo using synthetic antisense oligonucleotides or mimics needs to be stable in serum and avoid enzymatic degradation and renal clearance. In addition, miRNA needs to be delivered specifically to the target organ in order to minimize off-target effects, i.e., toxicity in normal tissues and activation of redundant signals because of miRNA networks. The short-term and long-term side effects need to be evaluated as well.[93] In contrast to the use of lentiviral vectors for in vivo delivery, which poses safety concerns, emerging exosomal delivery of extracellular miRNAs packaged in vesicles seems to be much more promising.[94-96]

With the emergence of the Genome wide associated study (GWAS) in the past decade, researchers and physicians better understand the pathogenesis of IBD within a broader genetic background.[97-99] Most of the genetic variants associated with particular autoimmune diseases are shared between other systemic and specific organ-targeted autoimmune and inflammatory diseases.[98-99] Key mechanisms defined from 163 IBD susceptible loci for IBD offer us a powerful tool to interconnect individual
miRNAs using a bioinformatics-generated miRNA target database.

The development of better therapeutic targets depends on our understanding of intestinal fibrosis in CD. Through collaboration with multiple IBD research centers, novel techniques and systematic biologic approaches, for example, GWAS together with whole exosome sequencing analysis, are elaborated into the current IBD research consortium to generate a huge database composed of patients' lab records and tissue banks that include patients' serum, plasma and surgical or biopsy specimens. Because of these resources, we may identify more specific gene loci as well as corresponding SNPs at related chromosomes based on underlying molecular and cellular mechanisms, thereby allowing for a tailored or individualized therapy regimen depending on the type and stage of $\mathrm{CD}$ in each patient.

In Fig. 2, I summarize the strategy used for miRNA design and study in translational biomedical research (Fig. 2).

\section{Conclusions}

Cellular components, such as mesenchymal cells, and core molecular processes, such as TGF- $\beta$ pathway, are critical in fibrotic events. miRNAs play a key role in the regulation of gene expres- 


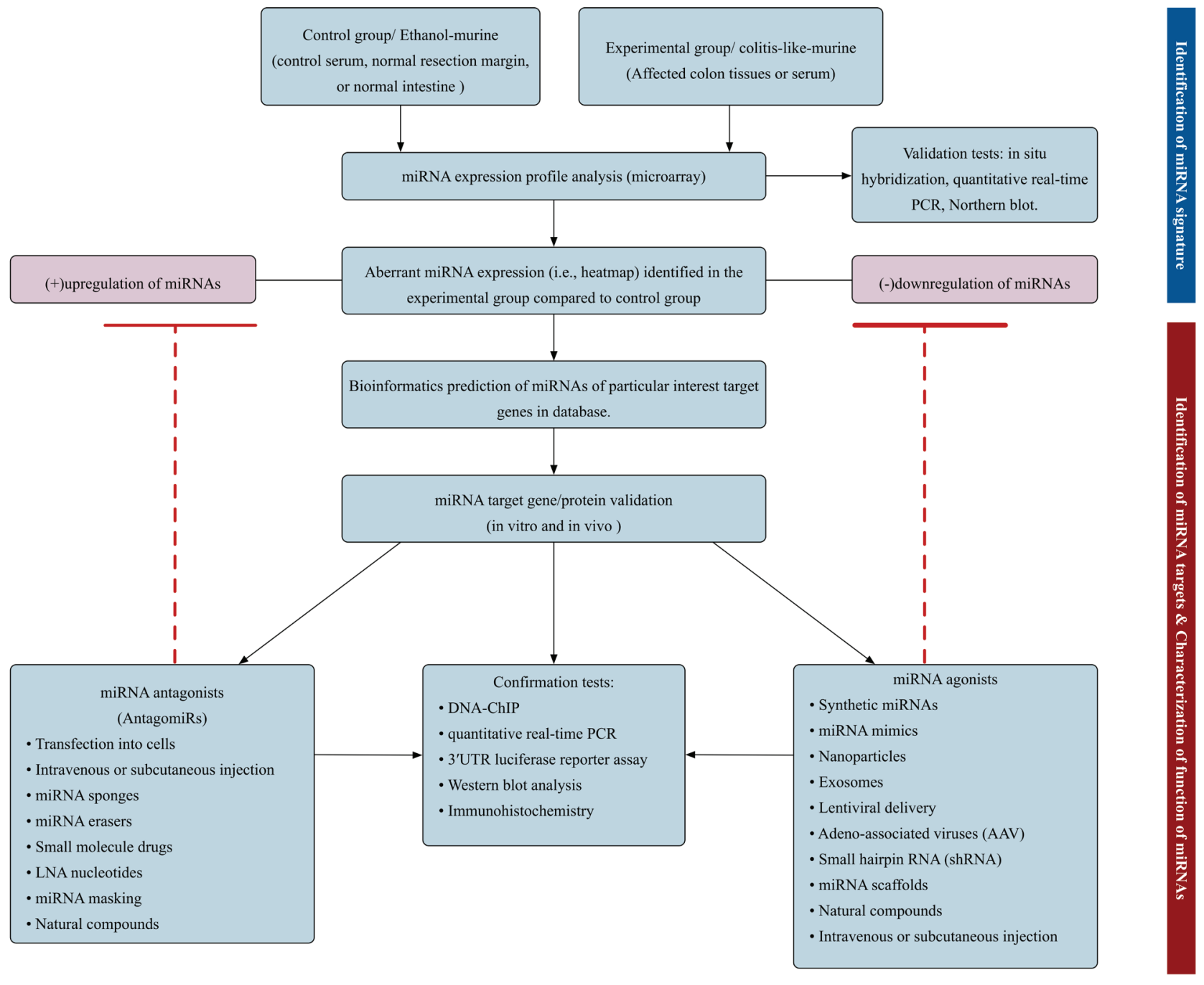

Fig. 2. MicroRNA research strategy in study of intestinal fibrosis in IBD.

sion at post-transcriptional levels. In this review, I presented the most recent findings on the differential expression of miRNAs in the regulation of diversified signal pathways in human diseases and animal models. Based on these functional studies, miRNAs in IBD could play a critical role in modulation of TGF- $\beta$ pathway at multiple levels in order to manage dysregulated intestinal homeostasis. I also address the potential challenges in miRNA studies and offer some suggestions to overcome these obstacles.

\section{Future Directions}

From a clinical perspective, intestinal fibrosis is not driven solely by chronic inflammation-mediated immunological response to stimulants. Control of inflammation through clinical intervention is not enough to combat complicated intestinal fibrosis. Better understanding of the pathogenesis of intestinal fibrosis in IBD requires integration of signal network information related to 163 risk loci, which were discovered by GWAS. In the near future, the study of cell-type specific and tissue specific expression of miRNAs may better our understanding of the function of miRNAs in the regulation of common fibrotic pathway, such as TGF- $\beta$ signaling. How we interpret miRNA data obtained from human and animal studies, which are related to IBD loci in GWAS findings, autophagy, and immune response, represents new opportunities for basic research in this field. Current strategies for miRNA research should be standardized across labs. These include strategies for selection of the right controls for patients with different subtypes, interpretation of miRNA data with correct miRNA internal controls, and uniformed protocols to process tissue samples.

\section{Acknowledgements}

I am grateful to Dr. Kuemmerle for critically reading the manuscript and constructive feedback during the preparation of this paper.

\section{Conflict of interest}

None. 


\section{Author contributions}

\section{Writing the paper $(\mathrm{CL})$.}

\section{References}

[1] Rubin DT, Mody R, Davis KL, Wang CC. Real-world assessment of therapy changes, suboptimal treatment and associated costs in patients with ulcerative colitis or Crohn's disease. Aliment Pharmacol Ther 2014;9(10):1143-55. doi: 10.1111/apt.12727.

[2] Park KT, Bass D. Inflammatory bowel disease-attributable costs and cost-effective strategies in the United States: a review. Inflamm Bowel Dis 2011;17(7):1603-9. doi: $10.1002 /$ ibd. 21488

[3] Thia KT, Loftus EV Jr, Sandborn WJ, Yang SK. An update on the epidemiology of inflammatory bowel disease in Asia. Am J Gastroenterol 2008;103(12):316782. doi: $10.1111 / \mathrm{j} .1572-0241.2008 .02158 . x$.

[4] Burisch J, Munkholm P. The epidemiology of inflammatory bowel disease. Scand J Gastroenterol 2015;50(8):942-51. doi: 10.3109/00365521.2015.1014407.

[5] Ananthakrishnan AN. Epidemiology and risk factors for IBD. Nat Rev Gastroenterol Hepatol 2015;12(4):205-17. doi: 10.1038/nrgastro.2015.34.

[6] Regan MC, Flavin BM, Fitzpatrick JM, O'Connell PR. Stricture formation in Crohn's disease: the role of intestinal fibroblasts. Ann Surg 2000;231(1):46-50. doi: 10.1097/00000658-200001000-00007.

[7] Rieder F, Zimmermann EM, Remzi FH, Sandborn WJ. Crohn's disease complicated by strictures: a systematic review. Gut 2013;62(7):1072-84. doi: 10.1136/ gutjnl-2012-304353.

[8] Rieder F, Brenmoehl J, Leeb S, Schölmerich J, Rogler G. Wound healing and fibrosis in intestinal disease. Gut 2007;56(1):130-9. doi: 10.1136/ gut.2006.090456.

[9] Burke JP, Mulsow JJ, O'Keane C, Docherty NG, Watson RW, O'Connell PR. Fibrogenesis in Crohn's disease. Am J Gastroenterol 2007;102(2):439-48. doi: 10.1111/j.1572-0241.2006.01010.x.

[10] Li C, Kuemmerle JF. Mechanisms that mediate the development of fibrosis in patients with Crohn's disease. Inflamm Bowel Dis 2014;20(7):1250-8. doi: 10.1097/MIB.0000000000000043

[11] Enocha S, Leaper DJ. Basic science of wound healing. Surgery (Oxford) 2005;23:37-42. doi: 10.1383/surg.23.2.37.60352.

[12] Broughton G, Janis JE, Attinger CE. The basic science of wound healing. Plast Reconstr Surg 2006;117(7 Suppl):12S-34S. doi: 10.1097/01. prs.0000225430.42531.c2.

[13] Arpino V, Brock M, Gill SE. The role of TIMPs in regulation of extracellular matrix proteolysis. Matrix Biol 2015;44:247-54. doi: 10.1016/j.matbio.2015.03.005

[14] Medina C, Radomski MW. Role of matrix metalloproteinases in intestinal inflammation. J Pharmacol Exp Ther 2006;318(3):933-8. doi: 10.1124/ jpet.106.103465.

[15] O'Sullivan S, Gilmer JF, Medina C. Matrix Metalloproteinases in Inflammatory Bowel Disease: An Update. Mediators Inflamm 2015;2015:964131. doi: 10.1155/2015/964131.

[16] Powell DW, Adegboyega PA, Di Mari JF, Mifflin RC. Epithelial cells and their neighbors I. Role of intestinal myofibroblasts in development, repair, and cancer. Am J Physiol Gastrointest Liver Physiol 2005;289(1):G2-G7. doi: 10.1152/ ajpgi.00075.2005.

[17] Powell DW, Pinchuk IV, Saada JI, Chen X, Mifflin RC. Mesenchymal cells of the intestinal lamina propria. Annu Rev Physiol 2011;73:213-37. doi: 10.1146/ annurev.physiol.70.113006.100646.

[18] Mifflin RC, Pinchuk IV, Saada JI, Powell DW. Intestinal myofibroblasts: targets for stem cell therapy. Am J Physiol Gastrointest Liver Physiol 2011;300(5):G684 96. doi: 10.1152/ajpgi.00474.2010.

[19] Darby IA, Laverdet B, Bonté F, Desmoulière A. Fibroblasts and myofibroblasts in wound healing. Clin Cosmet Investig Dermatol 2014;7:301-11.

[20] Meier JK, Scharl M, Miller SN, Brenmoehl J, Hausmann M, Kellermeier S, et al. Specific differences in migratory function of myofibroblasts isolated from Crohn's disease fistulae and strictures. Inflamm Bowel Dis 2011;17(1):202-12. doi: 10.1002/ibd.21344

[21] Walton KL, Holt L, Sartor RB. Lipopolysaccharide activates innate immune responses in murine intestinal myofibroblasts through multiple signaling pathways. Am J Physiol Gastrointest Liver Physiol 2009;296(3):G601-11. doi: 10.1152/ ajpgi.00022.2008.

[22] Bourgier C, Haydont V, Milliat F, François A, Holler V, Lasser P, et al. Inhibition of Rho kinase modulates radiation induced fibrogenic phenotype in intestinal smooth muscle cells through alteration of the cytoskeleton and connective tissue growth factor expression. Gut 2005;54(3):336-43. doi: 10.1136/ gut.2004.051169.

[23] McKaig BC, Hughes K, Tighe PJ, Mahida YR. Differential expression of TGF-beta isoforms by normal and inflammatory bowel disease intestinal myofibroblasts. Am J Physiol Cell Physiol 2002;282(1):C172-82. doi: 10.1152/ ajpcell.00048.2001

24] Stanzel RD, Lourenssen S, Nair DG, Blennerhassett MG. Mitogenic factors promoting intestinal smooth muscle cell proliferation. Am J Physiol Cell Physio 2010;299(4):C805-17. doi: 10.1152/ajpcell.00086.2010.

[25] Coco DP, Hirsch MS, Hornick JL. Smoothelin is a specific marker for smooth muscle neoplasms of the gastrointestinal tract. Am J Surg Pathol 2009;33(12):1795-801. doi: 10.1097/PAS.0b013e3181b76477.

[26] Rockey DC, Bell PD, Hill JA. Fibrosis-a common pathway to organ injury and failure. N Engl J Med 2015;372(12):1138-49. doi: 10.1056/NEJMra1300575.

[27] Pohlers D, Brenmoehl J, Löffler I, Müller CK, Leipner C, Schultze-Mosgau S, et al. TGF-beta and fibrosis in different organs - molecular pathway imprints. Biochim Biophys Acta 2009;1792(8):746-56. doi: 10.1016/j.bbadis.2009.06.004

[28] Verrecchia F, Mauviel A. Transforming growth factor-beta and fibrosis. World J Gastroenterol 2007;13(22):3056-62.

[29] Leask A, Abraham DJ. TGF-beta signaling and the fibrotic response. FASEB J 2004;18(7):816-27. doi: 10.1096/fj.03-1273rev.

[30] Branton MH, Kopp JB. TGF-beta and fibrosis. Microbes Infect 1999;1(15):134965. doi: 10.1016/S1286-4579(99)00250-6.

[31] Feagins LA. Role of transforming growth factor- $\beta$ in inflammatory bowel disease and colitis-associated colon cancer. Inflamm Bowel Dis 2010;16(11):1963-8. doi: 10.1002/ibd.21281.

[32] Li C, Flynn RS, Grider JR, Murthy KS, Kellum JM, Akbari H, et al. Increased activation of latent TGF- $\beta 1$ by $\alpha \mathrm{V} \beta 3$ in human Crohn's disease and fibrosis in TNBS colitis can be prevented by cilengitide. Inflamm Bowel Dis 2013;19(13):2829-39. doi: 10.1097/MIB.0b013e3182a8452e.

[33] Nishimura SL. Integrin-mediated transforming growth factor-beta activation, a potential therapeutic target in fibrogenic disorders. Am J Pathol 2009;175(4):1362-70. doi: 10.2353/ajpath.2009.090393.

[34] Vallance BA, Gunawan MI, Hewlett B, Bercik P, Van Kampen C, Galeazzi F, et al. TGF-betal gene transfer to the mouse colon leads to intestinal fibrosis. Am J Physiol Gastrointest Liver Physiol 2005;289(1):G116-28, doi: 10.1152 ajpgi.00051.2005

[35] Di Sabatino A, Jackson CL, Pickard KM, Buckley M, Rovedatti L, Leakey NA, et al. Transforming growth factor beta signalling and matrix metalloproteinases in the mucosa overlying Crohn's disease strictures. Gut 2009;58(6):777-89. doi: 10.1136/gut.2008.149096.

[36] Butz H, Rácz K, Hunyady L, Patócs A. Crosstalk between TGF- $\beta$ signaling and the microRNA machinery. Trends Pharmacol Sci 2012;33(7):382-93. doi: 10.1016/j.tips.2012.04.003

[37] Chung AC, Lan HY. MicroRNAs in renal fibrosis. Front Physiol 2015;6:50. doi 10.3389/fphys.2015.00050

[38] Winter J, Jung S, Keller S, Gregory RI, Diederichs S. Many roads to maturity: microRNA biogenesis pathways and their regulation. Nat Cell Biol 2009;11(3):228-34. doi: 10.1038/ncb0309-228

[39] Inui M, Martello G, Piccolo S. MicroRNA control of signal transduction. Nat Rev Mol Cell Biol 2010;11(4):252-63. doi: 10.1038/nrn2804.

[40] Kalla R, Ventham NT, Kennedy NA, Quintana JF, Nimmo ER, Buck AH, et al. MicroRNAs: new players in IBD. Gut 2015;64(3):504-17. doi: 10.1136 gutjnl-2014-307891.

[41] Chapman CG, Pekow J. The emerging role of miRNAs in inflammatory bowel disease: a review. Therap Adv Gastroenterol 2015;8(1):4-22. doi: $10.1177 / 1756283 \times 14547360$

42] Zanotti S, Gibertini S, Curcio M, Savadori P, Pasanisi B, Morandi L, et al. Opposing roles of miR-21 and miR-29 in the progression of fibrosis in Duchenne muscular dystrophy. Biochim Biophys Acta 2015;1852(7):1451-64. doi 10.1016/j.bbadis.2015.04.013

[43] Cushing L, Kuang P, Lü J. The role of miR-29 in pulmonary fibrosis. Biochem Cell Biol 2015;93(2):109-18. doi: 10.1139/bcb-2014-0095.

[44] Wu F, Dong F, Arendovich N, Zhang J, Huang Y, Kwon JH. Divergent influence of microRNA-21 deletion on murine colitis phenotypes. Inflamm Bowel Dis 2014;20(11):1972-85. doi: 10.1097/MIB.0000000000000201.

[45] Däbritz J, Menheniott TR. Linking immunity, epigenetics, and cancer in inflammatory bowel disease. Inflamm Bowel Dis 2014;20(9):1638-54. doi: 10.1097 MIB.0000000000000063.

[46] Mann J, Mann DA. Epigenetic regulation of wound healing and fibrosis. Curr Opin Rheumatol 2013;25(1):101-7. doi: 10.1097/BOR.0b013e32835b13e1

[47] Scarpa M, Stylianou E. Epigenetics: Concepts and relevance to IBD pathogenesis. Inflamm Bowel Dis 2012;18(10):1982-96. doi: 10.1002/ibd.22934.

[48] Chen BF, Suen YK, Gu S, Li L, Chan WY. A miR-199a/miR-214 self-regulatory network via PSMD10, TP53 and DNMT1 in testicular germ cell tumor. Sci Rep 2014;4:6413. doi: 10.1038/srep06413.

[49] Wu F, Zikusoka M, Trindade A, Dassopoulos T, Harris ML, Bayless TM, et al. MicroRNAs are differentially expressed in ulcerative colitis and alter expression of macrophage inflammatory peptide-2 alpha. Gastroenterology 2008;135(5):1624-35. doi: 10.1053/j.gastro.2008.07.068

[50] Shaked I, Meerson A, Wolf Y, Avni R, Greenberg D, Gilboa-Geffen A, et al. MicroRNA-124 regulates STAT3 expression and is down-regulated in colon tissue of pediatric patients with ulcerative colitis. Gastroenterology 2013;145:842-52 e2. doi: 10.1053/j.gastro.2013.07.001

51] Yang $\mathrm{Y}$, Ma Y, Shi C, Chen $\mathrm{H}$, Zhang $\mathrm{H}$, Chen $\mathrm{N}$, et al. Overexpression of miR- 
21 in patients with ulcerative colitis impairs intestinal epithelial barrier function through targeting the Rho GTPase RhoB. Biochem Biophys Res Commun 2013;434(4):746-52. doi: 10.1016/j.bbrc.2013.03.122.

[52] Sadler T, Scarpa M, Rieder F, West G, Stylianou E. Cytokine-induced chromatin modifications of the type I collagen alpha 2 gene during intestinal endothelial-tomesenchymal transition. Inflamm Bowel Dis 2013;19(7):1354-64. doi: 10.1097/ MIB.0b013e318281f37a.

[53] Li C, Grider JR, Kuemmerle JF. 361 Antagomir to MicroRNA-21 Reverses the Loss of Negative TGF- Signaling From Inappropriately Decreased Smad7 Expression in Crohn's Disease, and Decreases Excess Collagen, CTGF, IGF-I and Fibrosis in TNBS-Induced Colitis. Gastroenterology 2012;142:S-85.

[54] Li Q, Zhang D, Wang Y, Sun P, Hou X, Larner J, et al. MiR-21/Smad 7 signaling determines TGF- $\beta 1$-induced CAF formation. Sci Rep 2013;3:2038.

[55] Shi C, Liang Y, Yang J, Xia Y, Chen H, Han H, et al. MicroRNA-21 knockout improve the survival rate in DSS induced fatal colitis through protecting against inflammation and tissue injury. PLoS One 2013;8(6):e66814. doi: 10.1371/journal.pone.0066814

[56] Ludwig K, Fassan M, Mescoli C, Pizzi M, Balistreri M, Albertoni L, et al. PDCD4/miR-21 dysregulation in inflammatory bowel disease-associated carcinogenesis. Virchows Arch 2013;462(1):57-63. doi: 10.1007/s00428-0121345-5.

[57] Brain O, Owens BM, Pichulik T, Allan P, Khatamzas E, Leslie A, et al. The intracellular sensor NOD2 induces microRNA-29 expression in human dendritic cells to limit IL-23 release. Immunity 2013;39(3):521-36. doi: 10.1016/j.immuni.2013.08.035.

[58] Seiderer J, Brand S, Herrmann KA, Schnitzler F, Hatz R, Crispin A, et al. Predictive value of the CARD15 variant $1007 \mathrm{fs}$ for the diagnosis of intestinal stenoses and the need for surgery in Crohn's disease in clinical practice: results of a prospective study. Inflamm Bowel Dis 2006;12(12):1114-21. doi: 10.1097/01. mib.0000235836.32176.5e

[59] Rehman A, Sina C, Gavrilova O, Häsler R, Ott S, Baines JF, et al. Nod2 is essential for temporal development of intestinal microbial communities. Gut 2011;60(10):1354-62. doi: 10.1136/gut.2010.216259.

[60] Nijhuis A, Biancheri P, Lewis A, Bishop CL, Giuffrida P, Chan C, et al. In Crohn's disease fibrosis-reduced expression of the miR-29 family enhances collagen expression in intestinal fibroblasts. Clin Sci (Lond) 2014;127(5):341-50. doi: $10.1042 / \mathrm{CS} 20140048$.

[61] Li C, Kuemmerle JF. Increased pro-fibrotic miR-21 and decreased anti-fibrotic miR-29b regulate TGF- $\beta 1$ signaling, TGF- $\beta 1$-dependent collagen-I expression and fibrosis in fibrostenotic (B2) Crohn's disease. Inflamm Bowel Dis 2014;12:S17-8.

[62] Zhang Y, Huang XR, Wei LH, Chung AC, Yu CM, Lan HY. miR-29b as a therapeutic agent for angiotensin II-induced cardiac fibrosis by targeting TGF- $\beta$ / Smad3 signaling. Mol Ther 2014;22(5):974-85. doi: 10.1038/mt.2014.25.

[63] Korpal M, Lee ES, Hu G, Kang Y. The miR-200 family inhibits epithelial-mesenchymal transition and cancer cell migration by direct targeting of E-cadherin transcriptional repressors ZEB1 and ZEB2. J Biol Chem 2008;283(22):14910-4. doi: $10.1074 / \mathrm{jbc}$.C 800074200 .

[64] Korpal M, Kang Y. The emerging role of miR-200 family of microRNAs in epithelial-mesenchymal transition and cancer metastasis. RNA Biol 2008;5(3):1159. doi: $10.4161 /$ rna.5.3.6558.

[65] Chen Y, Xiao Y, Ge W, Zhou K, Wen J, Yan W, et al. miR-200b inhibits TGF$\beta 1$-induced epithelial-mesenchymal transition and promotes growth of intestinal epithelial cells. Cell Death Dis 2013;4:e541. doi: 10.1038/cddis.2013.22.

[66] Wang B, Koh P, Winbanks C, Coughlan MT, McClelland A, Watson A, et al. miR-200a Prevents renal fibrogenesis through repression of TGF- $\beta 2$ expression. Diabetes 2011;60(1):280-7. doi: 10.2337/db10-0892.

[67] Chuang AY, Chuang JC, Zhai Z, Wu F, Kwon JH. NOD2 expression is regulated by microRNAs in colonic epithelial HCT116 cells. Inflamm Bowel Dis 2014;20(1):126-35. doi: 10.1097/01.MIB.0000436954.70596.9b.

[68] Kato M, Zhang J, Wang M, Lanting L, Yuan H, Rossi JJ, et al. MicroRNA-192 in diabetic kidney glomeruli and its function in TGF-beta-induced collagen expression via inhibition of E-box repressors. Proc Natl Acad Sci U S A 2007;104(9):3432-7. doi: 10.1073/pnas.0611192104.

[69] Chung AC, Huang XR, Meng X, Lan HY. miR-192 mediates TGF-beta/Smad3driven renal fibrosis. J Am Soc Nephrol 2010;21(8):1317-25. doi: 10.1681/ ASN.2010020134.

[70] Kato M, Putta S, Wang M, Yuan H, Lanting L, Nair I, et al. TGF-beta activates Akt kinase through a microRNA-dependent amplifying circuit targeting PTEN. Nat Cell Biol 2009;11(7):881-9. doi: 10.1038/ncb1897.

[71] Chung AC, Dong Y, Yang W, Zhong X, Li R, Lan HY. Smad7 suppresses renal fibrosis via altering expression of TGF- $\beta /$ Smad3-regulated microRNAs. Mol Ther 2013;21(2):388-98. doi: 10.1038/mt.2012.251.

[72] Qian X, Yu J, Yin Y, He J, Wang L, Li Q, et al. MicroRNA-143 inhibits tumor growth and angiogenesis and sensitizes chemosensitivity to oxaliplatin in colorectal cancers. Cell Cycle 2013;12(9):1385-94. doi: 10.4161/cc.24477.

[73] Chivukula RR, Shi G, Acharya A, Mills EW, Zeitels LR, Anandam JL, et al. An essential mesenchymal function for miR-143/145 in intestinal epithelial regeneration. Cell 2014;157(5):1104-16. doi: 10.1016/j.cell.2014.03.055.

[74] Josse C, Bouznad N, Geurts P, Irrthum A, Huynh-Thu VA, Servais L, et al. Iden- tification of a microRNA landscape targeting the PI3K/Akt signaling pathway in inflammation-induced colorectal carcinogenesis. Am J Physiol Gastrointes Liver Physiol 2014;306(3):G229-43. doi: 10.1152/ajpgi.00484.2012.

[75] Chan YC, Banerjee J, Choi SY, Sen CK. miR-210: the master hypoxamir. Microcirculation 2012;215-23.

[76] Wang H, Flach H, Onizawa M, Wei L, McManus MT, Weiss A. Negative regulation of Hifla expression and TH17 differentiation by the hypoxia-regulated microRNA miR-210. Nat Immunol 2014;15(4):393-401. doi: 10.1038/ni.2846.

[77] Bodempudi V, Hergert P, Smith K, Xia H, Herrera J, Peterson M, et al. miR-210 promotes IPF fibroblast proliferation in response to hypoxia. Am J Physiol Lung Cell Mol Physiol 2014;307(4):L283-94. doi: 10.1152/ajplung.00069.2014.

[78] Das LM, Torres-Castillo MD, Gill T, Levine AD. TGF- $\beta$ conditions intestinal T cells to express increased levels of miR-155, associated with down-regulation of IL-2 and itk mRNA. Mucosal Immunol 2013;6(1):167-76. doi: 10.1038 mi.2012.60.

[79] Singh UP, Murphy AE, Enos RT, Shamran HA, Singh NP, Guan H, et al. miR-155 deficiency protects mice from experimental colitis by reducing T helper type 1 / type 17 responses. Immunology 2014;143(3):478-89. doi: 10.1111/imm.12328.

[80] Min M, Peng L, Yang Y, Guo M, Wang W, Sun G. MicroRNA-155 is involved in the pathogenesis of ulcerative colitis by targeting FOXO3a. Inflamm Bowel Dis 2014;20(4):652-9. doi: 10.1097/MIB.0000000000000009.

[81] Pathak S, Grillo AR, Scarpa M, Brun P, D’Incà R, Nai L, et al. MiR-155 modulates the inflammatory phenotype of intestinal myofibroblasts by targeting SOCS1 in ulcerative colitis. Exp Mol Med 2015;47:e164. doi: 10.1038/ emm.2015.21

[82] Paraskevi A, Theodoropoulos G, Papaconstantinou I, Mantzaris G, Nikiteas N, Gazouli M. Circulating MicroRNA in inflammatory bowel disease. J Crohns Colitis 2012;6(9):900-4. doi: 10.1016/j.crohns.2012.02.006

[83] Zhang PX, Cheng J, Zou S, D'Souza AD, Koff JL, Lu J, et al. Pharmacological modulation of the AKT/microRNA-199a-5p/CAV1 pathway ameliorates cystic fibrosis lung hyper-inflammation. Nat Commun 2015;6:6221. doi: 10.1038 ncomms 7221

[84] Lino Cardenas CL, Henaoui IS, Courcot E, Roderburg C, Cauffiez C, Aubert S, et al. miR-199a-5p Is upregulated during fibrogenic response to tissue injury and mediates TGFbeta-induced lung fibroblast activation by targeting caveolin-1. PLoS Genet 2013;9(2):e1003291. doi: 10.1371/journal.pgen.1003291.

[85] Murakami Y, Toyoda H, Tanaka M, Kuroda M, Harada Y, Matsuda F, et al. The progression of liver fibrosis is related with overexpression of the miR-199 and 200 families. PLoS One 2011;6(1):e16081 doi: 10.1371/journal pone.0016081.

[86] Mussnich P, Rosa R, Bianco R, Fusco A, D'Angelo D. MiR-199a-5p and miR375 affect colon cancer cell sensitivity to cetuximab by targeting PHLPP1. Expert Opin Ther Targets 2015;19(8):1017-26. doi: 10.1517/14728222.2015.1057569.

[87] Olive V, Li Q, He L. mir-17 92: a polycistronic oncomir with pleiotropic functions. Immunol Rev 2013;253:158-66. doi: 10.1111/imr.12054.

[88] Li J, Yang S, Yan W, Yang J, Qin YJ, Lin XL, et al. MicroRNA-19 triggers epithelial-mesenchymal transition of lung cancer cells accompanied by growth inhibition. Lab Invest 2015;95(9):1056-70. doi: 10.1038/labinvest.2015.76.

[89] Cellura D, Pickard K, Quaratino S, Parker H, Strefford JC, Thomas GJ, et al. miR-19-Mediated Inhibition of Transglutaminase-2 Leads to Enhanced Invasion and Metastasis in Colorectal Cancer. Mol Cancer Res 2015;13(7):1095-105. doi: 10.1158/1541-7786.MCR-14-0466.

[90] Lewis A, Mehta S, Hanna LN, Rogalski LA, Jeffery R, Nijhuis A, et al. Low Serum Levels of MicroRNA-19 Are Associated with a Stricturing Crohn's Disease Phenotype. Inflamm Bowel Dis 2015;21(8):1926-34. doi: 10.1097/ MIB.0000000000000443.

[91] Dakhlallah D, Batte K, Wang Y, Cantemir-Stone CZ, Yan P, Nuovo G, et al. Epigenetic regulation of miR-17 92 contributes to the pathogenesis of pulmonary fibrosis. Am J Respir Crit Care Med 2013;187(4):397-405. doi: 10.1164 rccm.201205-08880C

[92] Cheng X, Zhang X, Su J, Zhang Y, Zhou W, Zhou J, et al. miR-19b downregulates intestinal SOCS3 to reduce intestinal inflammation in Crohn's disease. Sc Rep 2015;5:10397. doi: 10.1038/srep10397.

[93] Pecot CV, Calin GA, Coleman RL, Lopez-Berestein G, Sood AK. RNA interference in the clinic: challenges and future directions. Nat Rev Cancer 2011;11:5967. doi: 10.1038/nrc2966.

[94] Kourembanas S. Exosomes: vehicles of intercellular signaling, biomarkers, and vectors of cell therapy. Annu Rev Physiol 2015;77:13-27. doi: 10.1146/annurevphysiol-021014-071641

[95] Yoon C, Kim J, Park G, Kim S, Kim D, Hur DY, et al. Delivery of miR-155 to retinal pigment epithelial cells mediated by Burkitt's lymphoma exosomes. Tumour Biol 2015; Jul 26.

[96] Aryani A, Denecke B. Exosomes as a Nanodelivery System: a Key to the Future of Neuromedicine? Mol Neurobiol 2014; Dec 15

[97] Baumgart S. Crohn's disease. Lancet 2012;380(9853):1590-605. doi: 10.1016 S0140-6736(12)60026-9

[98] Lees CW, Barrett JC, Parkes M, Satsangi J. New IBD genetics: common pathways with other diseases. Gut 2011;60(12):1739-53. doi: 10.1136/gut.2009.199679.

[99] Zhernakova A, Withoff S, Wijmenga C. Clinical implications of shared genetics and pathogenesis in autoimmune diseases. Nat Rev Endocrinol 2013;9(11):64659. doi: 10.1038 /nrendo.2013.161 